\title{
Three-dimensional finite element analysis for determining the stress distribution after loading the bone surface with two-component mini-implants of varying length
}

\author{
Bohm Choi, DDS, MSD, ${ }^{\text {a }}$ Dong-Ok Lee, DDS, MSD, ${ }^{\text {b }}$ Sung-Seo Mo, DDS, MSD, PhD, ${ }^{\mathrm{c}}$ \\ Seong-Hun Kim, DDS, MSD, PhD, ${ }^{d}$ Ki-Ho Park, DDS, MSD, PhD, ${ }^{d}$ Kyu-Rhim Chung, DDS, MSD, PhD, \\ Gerald Nelson, DDS, ${ }^{\mathrm{f}}$ Seong Ho Han, DMD, $\mathrm{MS}^{\mathrm{g}}$
}

\begin{abstract}
Objective: To evaluate the extent and aspect of stress to the cortical bone after application of a lateral force to a two-component orthodontic mini-implant (OMI, mini-implant) by using three-dimensional finite element analysis (FEA). Methods: The 3D-finite element models consisted of the maxilla, maxillary first molars, second premolars, and OMls. The screw part of the OMl had a diameter of $1.8 \mathrm{~mm}$ and length of $8.5 \mathrm{~mm}$ and was placed between the roots of the upper second premolar and the first molar. The cortical bone thickness was set to $1 \mathrm{~mm}$. The head part of the OMl was available in 3 sizes: $1 \mathrm{~mm}, 2 \mathrm{~mm}$, and $3 \mathrm{~mm}$. After a $2 \mathrm{~N}$ lateral force was applied to the center of the head part, the stress distribution and magnitude were analyzed using FEA. Results: When the head part of the OMl was friction fitted (tapped into place) into the inserted screw part, the stress was uniformly distributed over the surface where the head part was inserted. The extent of the minimum principal stress suggested that the length of the head part was proportionate with the amount of stress to the cortical bone; the stress varied between 10.84 and 15.33 MPa. Conclusions: These results suggest that the stress level at the cortical bone around the OMI does not have a detrimental influence on physiologic bone remodeling. (Korean $J$ Orthod 2011;41(6): 423-430)
\end{abstract}

Key words: Osseointegration, Mini-implant, Finite element analysis, Von-Mises stress

${ }^{a}$ Clinical Assistant Professor, Department of Prosthodontics, Yeouido St. Mary's Hospital, The Catholic University of Korea. ${ }^{\text {bPrivate Practice. }}$

'Associate Professor, Department of Orthodontics, Yeouido St. Mary's Hospital, The Catholic University of Korea.

${ }^{d}$ Assistant Professor, Department of Orthodontics, School of Dentistry, Kyung Hee University.

eProfessor, Department of Orthodontics, School of Clinical Dental Scinece, Ajou University.

'Clinical Professor, Department of Orofacial Science, University of California in San Francisco.

${ }^{9}$ Clinical Assistant Professor, Department of Orthodontics, St. Vincent Hospital, The Catholic University of Korea. Corresponding author: Seong Ho Han.

Department of Orthodontics, St. Vincent Hospital, The Catholic University of Korea, 93-6 Paldal-gu, Ji-dong. Suwon 442-723, Korea.

+82 31249 7670: e-mail, seonghh@hotmail.com.

Received May 8, 2011: Last Revision October 15, 2011: Accepted November 1, 2011.

http://dx.doi.org/10.4041/kjod.2011.41.6.423

\section{INTRODUCTION}

In orthodontics, anchorage for inhibiting the movement of teeth has always been an important consideration. The conventional methods of temporary anchorage include headgears, elastics, Nance devices, and lingual arches. However, these methods have limitations such as esthetic concerns, cooperation problems, and adverse effects. Recently, temporary skeletal anchorage devices (TSADs) such as osseointegrated miniimplants, miniplates, and mini-screws have been widely studied. ${ }^{1-3}$ Clinicians prefer using mini-screws (machined screw surface) and mini-implants (coated screw surface) since they are easy to place and remove and 

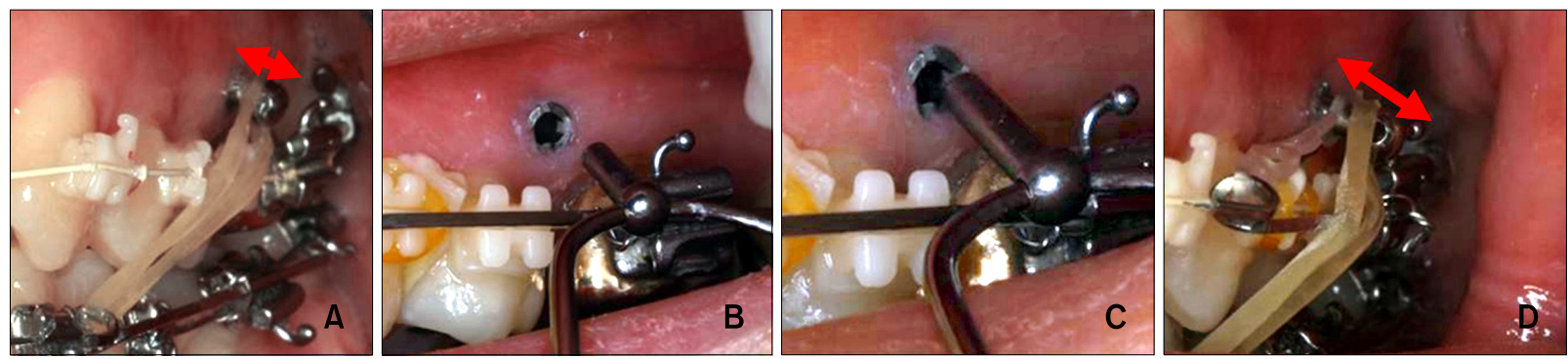

Fig 1. When both intermaxillary elastic and intramaxillary elastic cannot be applied simultaneously, the head part of the C-implant can be easily changed from $1 \mathrm{~mm}$ to $2 \mathrm{~mm}$. A, The $1 \mathrm{~mm}$-long head part of the C-implant may not leave additional space for concurrent use of the second elastics; B, the head part of the C-implant can be easily removed; C, a new longer head part $(2 \mathrm{~mm})$ can be inserted to the screw part; $\mathbf{D}$, both elastics can now be engaged to the C-implant simultaneously.

can enhance the biomechanical effects. ${ }^{3-8}$

Orthodontic mini-implants (OMI) and mini-screws are of 2 types: one-component or two-component systems; these implants have a removable head (mini-implant) (Fig 1). The screw part of the mini-implant is also surface treated for better osseointegration, which allows the application of dynamic or rotational forces. $^{9-12}$ The head part of the mini-implant, from the top of the screw part to the hole in the head part, is available in 3 sizes: $1 \mathrm{~mm}, 2 \mathrm{~mm}$, and $3 \mathrm{~mm}$ (Fig 2). The mini-implant has also been used as a provisional or final prosthetic implant in children or patients who have insufficient space for holding a conventional dental implant. ${ }^{13}$ The stress distribution of external forces in one-component devices has been well studied, but finite element analysis (FEA) for two-component OMIs is lacking. ${ }^{14-21}$

FEA allows a thorough assessment of the response of both TSADs and bones experiencing orthodontic forces. Three-dimensional (3D) computer models can be used to simulate various conditions by varying the simulation parameters. The present study aimed to evaluate the stress distribution by using 3D FEA when the two-component OMIs with the 3 different head sizes are used. The results of this study will increase the understanding of clinicians using this type of OMIs.

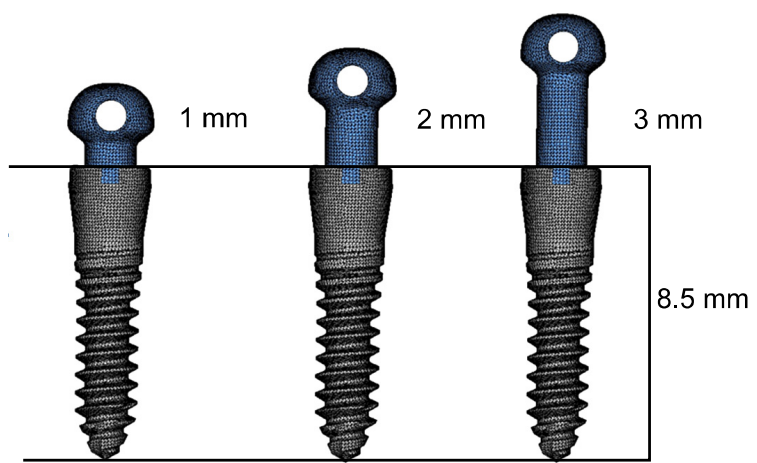

Fig 2. Geometric design of the two-component mini-implant system.

\section{MATERIAL AND METHODS}

\section{Construction of the FE model}

\section{Model configuration}

The FE model comprised a two-component OMI, teeth, and the maxillary bone. The bone was scaled as shown in the image provided by Digimation Ltd. (Lake Mary, FL, USA). The OMI used in this study had a diameter of $1.8 \mathrm{~mm}$ and length of $8.5 \mathrm{~mm}$ (mini-implant; CIMPLANT Co., Seoul, Korea). The implant was placed $4 \mathrm{~mm}$ apical to the peak of the alveolar crest between the roots of the upper second premolar and the first molar. The mini-implant was inserted such that the top part of the screw thread became flush with the soft tissue. The cortical bone and periodontal ligament were scaled to a thickness of $1 \mathrm{~mm}$ and 0.2 

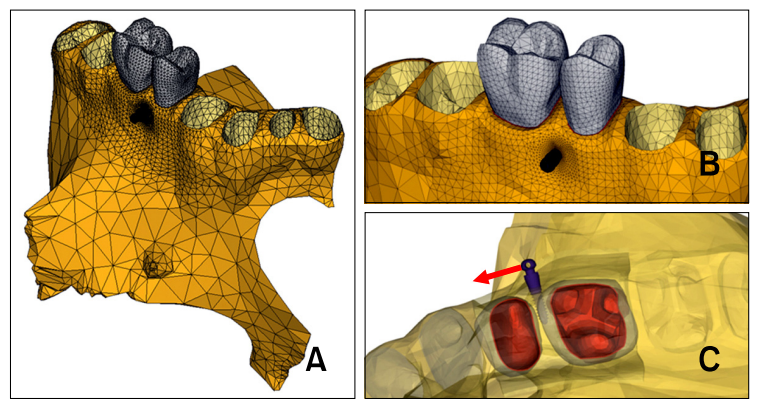

Fig 3. A, Schematic illustrations of the FE models containing the maxilla, maxillary first molar, maxillary second premolar, and mini-implant; $\mathbf{B}$, magnified images of the models containing the mini-implant, first molar, and second premolar; $\mathbf{C}$, the position of the mini-implant placement between the roots and the direction of lateral force loading.

$\mathrm{mm}$, respectively. Varying mesh sizes of the FE were used for the analysis in order to evaluate the stress distribution of the implant in detail. The implants were uniformly modeled with a mesh size of $0.1 \mathrm{~mm}$. The corresponding mesh part of the bone that connected with the implant was modeled such that it had the same size as that of the implant (i.e., $0.1 \mathrm{~mm}$ ). Lastly, the size of the implants was gradually increased until the external area of the bone ranged between 5 and 10 mm (Fig 3).

In the OMI, the head part was fitted to the screw part with a friction fit. This caused both the head and screw parts to become mutually deformed. Hence, when a load was applied to the head part, its stress was transmitted to the screw part via the friction of the connection. The friction fit of the head and screw parts was embodied through pre-simulation instead of simply connecting the 2 nodes of the parts. The initial stress generated by the friction fit was taken into account, and the amount of load transmission from the head to the screw part was calculated.

\section{Material properties and loading conditions}

In order to calculate the implant stress, we assumed that a bone is homogeneous, isotropic, and linearly elastic. The material properties were calculated using Young's modulus and Poisson's ratio, as has been re-
Table 1. Mechanical properties of each material

\begin{tabular}{lcc}
\hline & $\begin{array}{c}\text { Young's modulus } \\
(\mathrm{MPa})\end{array}$ & $\begin{array}{c}\text { Poisson's } \\
\text { ratio }\end{array}$ \\
\hline \hline Periodontal ligament & $5.0 \mathrm{E}-02$ & 0.49 \\
Trabecular bone & $1.8 \mathrm{E}+02$ & 0.45 \\
cortical bone & $1.2 \mathrm{E}+04$ & 0.33 \\
Teeth & $2.0 \mathrm{E}+04$ & 0.30 \\
Titanium & $1.15 \mathrm{E}+05$ & 0.33 \\
\hline
\end{tabular}

ported in previous studies (Table 1). ${ }^{22,23} \mathrm{~A}$ schematic illustration of the situation when a lateral force of $2 \mathrm{~N}$ is applied to the center of the hole in the head part of the mini-implant is shown in Fig 3C. In the present study, the entire maxillary bone was modeled. That is, the model extended into the boundary limit between the maxillary bone and the surrounding bone, thus preventing the distortion of stress that might have resulted if only a limited bony section was modeled.

The results of the FEA were tested using PAMMEDYSA version 2009 program (ESI, Paris, France).

\section{RESULTS}

\section{Stress distribution in an early stage}

The stress distribution of the implant when the head part is fitted by friction (tapped into place) after the implantation of the screw part is shown in Fig 4 . Because of the mechanical design of the fitted surfaces between the head and screw, the stress was mostly distributed in the receiving cavity of the screw. The insertion point of the head part was laterally tapered by $1.5^{\circ}$. Stress was uniformly distributed over the bone surface where the head part was inserted. Stress was greater in the upper part of the implant where the head and screw parts were coupled. The length of the head part did not affect the amount of stress or its distribution (Table 2).

Stress on the $\mathrm{OMI}$ after $2 \mathrm{~N}$ of lateral force was applied

The stress distribution pattern after the application of 


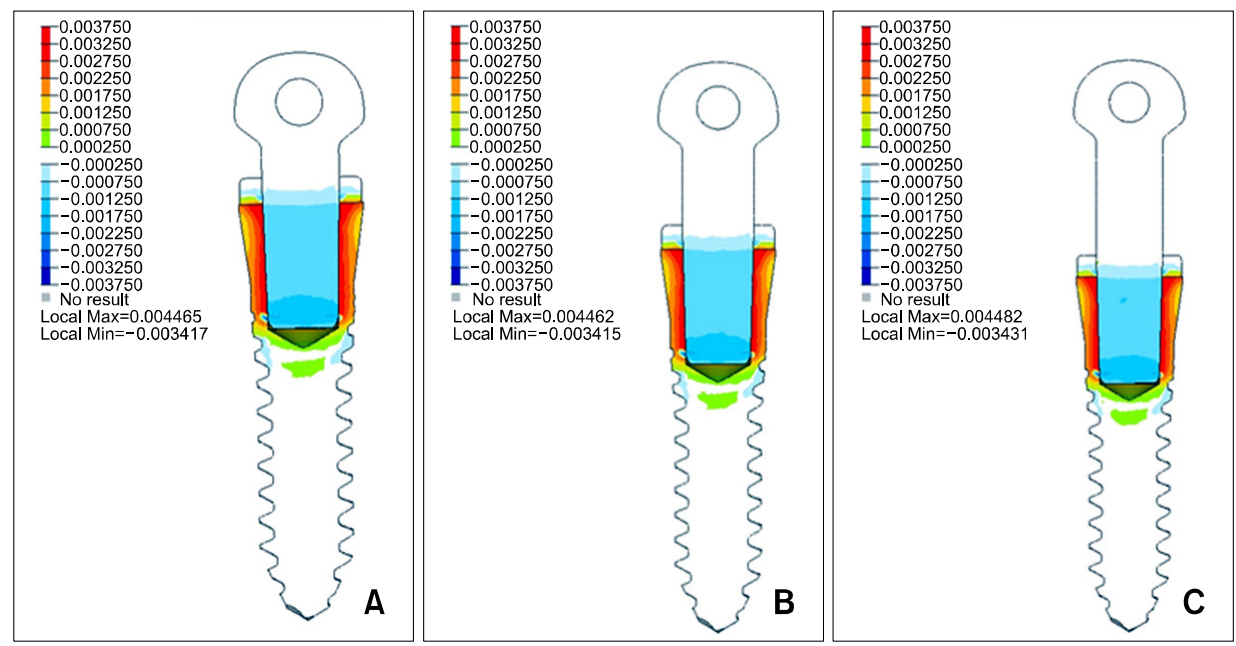

Fig 4. Stress distribution generated by friction fitting between the head part and screw part of the mini-implant. Contour plots of signed von Mises stress generated by placement of mini-implants having head lengths of $1 \mathrm{~mm}(\mathbf{A})$, $2 \mathrm{~mm}$ (B), and $3 \mathrm{~mm}(\mathbf{C})$.

Table 2. Stress distribution on bone and implant

\begin{tabular}{cccc}
\hline & \multicolumn{3}{c}{ Head size } \\
\cline { 2 - 4 } Variables & $1 \mathrm{~mm}$ & $2 \mathrm{~mm}$ & 3.48 \\
\hline \hline Signed Von Mises stress (Implant, Initial) & 4.47 & 4.46 & 28.65 \\
Signed Von Mises stress (Implant, 2NLF) & 19.19 & 23.30 & 15.33 \\
Minimum principle stress (Bone, 2NLF) & \multicolumn{2}{c}{ Maximum compressive stress } \\
Maximum principle stress (Bone, 2NLF) & 10.84 & 12.88 & 12.91 \\
\hline
\end{tabular}

Unit: MPa, 2NLF, 2 Newton of lateral force.

a lateral force of $2 \mathrm{~N}$ is shown in Fig 5. Tensile stress was generated on the side of the head part where the lateral force was applied; this led to the generation of maximum stress in the area of head and screw part coupling. Compressive stress was generated at the contralateral side of the screw receiving the lateral force. Tensile stress was generated in some areas of the screw part. Stress was also generated on the top area of the screw part that came in contact with the head part where compression stress was generated. The longer the head part, the greater was the stress. The stress at the head part increased in proportion to that at the screw part (Table 2).
Stress distribution on the bone after $2 \mathrm{~N}$ of lateral force was applied

Compressive stress was generated on the contralateral side of the cortical bone where the lateral force was applied. Tensile stress was generated on the cortical bone side where the lateral force was applied. Moreover, stress was greater at the contralateral side of the boundary between the cancellous bone and cortical bone to which the lateral force was applied. The length of the head part was correlated with the amount of stress generated across the implant as well as that generated in the cortical bone (Table 2). 


\section{DISCUSSION}

When placing a prosthetic implant in an edentulous area, determining the stress distribution of the occlusal load on the implant and the surrounding bone is important. Osseointegration is essential to ensure that the implant remains stable under the occlusal load. The objective of achieving osseointegration is to effectively distribute the load up to the depth of the bone. Many studies have determined the stress distribution after placement of prosthetic implants. ${ }^{24-27}$ Sertgöz and Güvener $^{24}$ used the 3D FE method to analyze the stress to the bone and implant surfaces after placement of implant-supported dentures. Skalak ${ }^{25}$ showed that the stress increases in proportion to the load applied to the implant; however, the increased load does not affect the phase of stress distribution. Moreover, researchers have shown how stress distribution is influenced by the size and shape of the implant as well as bony factors $^{27,28}$ such as bone density and cortical bone thickness. Results obtained by dental implant studies cannot be directly used to understand the changes occurring after the placement of mini-implants. This is because there are differences between dental implants and mini-implants. First, unlike dental implants, mini- implants are loaded immediately or within 4 weeks. Second, prosthetic implants are placed in the occlusal surface of the alveolar bone, while mini-implants are placed in the inter-radicular space. Third, the vector of the applied force is through the dental implant axis, while it is lateral to the mini-implant axis. Lastly, dental implants are permanent, while mini-implants are temporary and removed when not required. Similarly, the mini-implant differs from the one-component miniimplant with respect to the two-part design and thus requires an independent study. Seo et al. showed that the mean bone-to-implant contact (BIC) after the removal of a sandblasted, large-grit, and acid-etched (SLA) mini-implant was $52.6 \%$, indicating partial osseointegration. ${ }^{29}$ This suggests that the SLA mini-implant is resistant to heavy and dynamic forces, as well as to rotational movements produced by the intrusive movement of the retraction biomechanics. Moreover, Kim et al. showed that, during removal, SLA OMIs had relatively lower insertion torque and angular momentum but higher total energy than implants having a machined surface, suggesting that SLA mini-implants showed better osseointegration after insertion. ${ }^{13}$

The mini-implant head available in various sizes is exchangeable, and hence, the extent of the force applied can be varied without requiring an expensive inventory of implant devices. Implants with long head parts are useful for conducting intermaxillary fixation during jaw surgery, allowing multiple force applica-

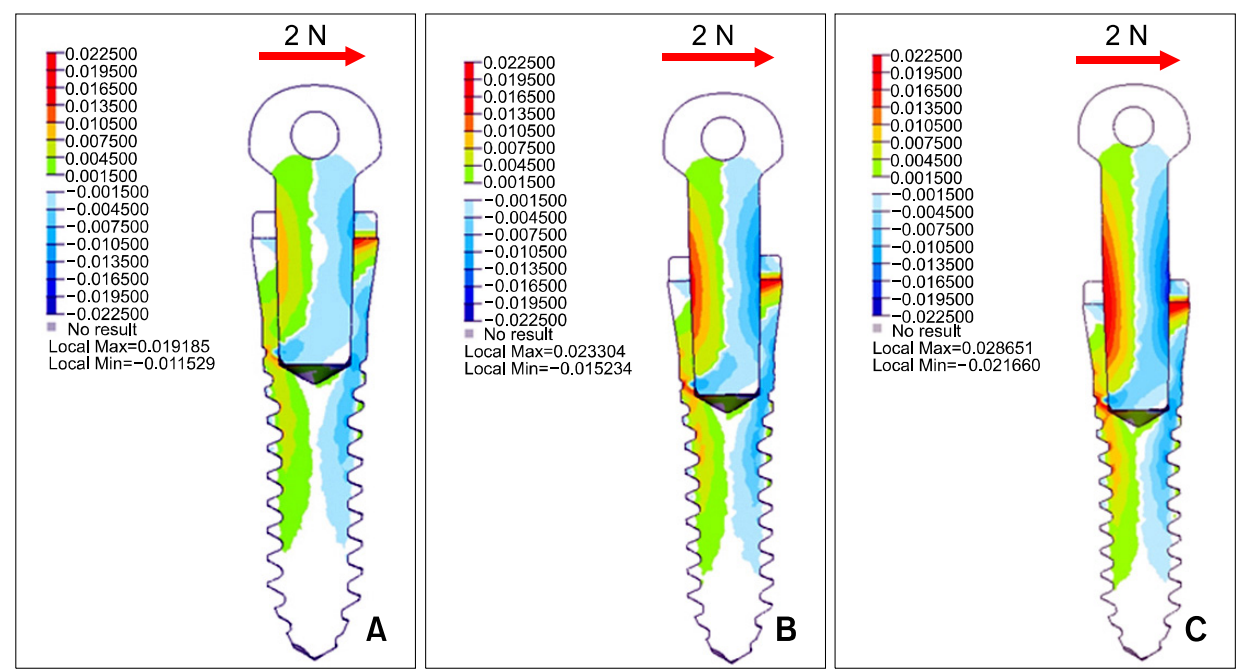

Fig 5. Contour plots of signed von Mises stress generated by mini-implants having head lengths of $1 \mathrm{~mm}(\mathbf{A}), 2 \mathrm{~mm}$ (B), and $3 \mathrm{~mm}(\mathbf{C})$ after a $2 \mathrm{~N}$ lateral force is applied. 
tions, facilitating an angulated vector of insertion, or allowing implant fixation in thick soft tissues such as the palate. ${ }^{10,30}$ The longer head part reduces the risk of screw loosening because of the surface treatment of the screw, thereby enhancing osseointegration.

Mini-implants can be used as a preliminary restorative aid when the morphology of the alveolar bone is not ideal. ${ }^{13,31} \mathrm{~A}$ two-component OMI can be used to provide anchorage for a prosthetic restoration.

The two-component OMI uses a friction fit to combine both the head and screw parts. Therefore, early determination of stress distribution is important. At the initial state, the head part length hardly affects stress distribution since the signed von Mises stress is 4.47 - 4.48 MPa. Although the stress distribution after the placement of two-component OMIs with different head lengths is similar, the extent of stress increases in proportion to the length of the head part (Fig 5 and Table 2).

We found that the compressive and tensile stress levels at the adjacent bone are mainly concentrated on the cortical bone area when a lateral force of $2 \mathrm{~N}$, which is commonly used in orthodontic practice, was applied. The stress value ranged from $8.95 \mathrm{MPa}$ to 15.33 $\mathrm{MPa}$, increasing in proportion to the length of the head part (Fig 6 and Table 2). According to a previous study, the physiologic limit for biological deformation of the cortical bone after placement of a one-component is $4,000 \mu$-strain $\left(0.4 \%\right.$ strain). ${ }^{32,33}$ That is, no damage to the cortical bone occurs during the remodeling process if the stress applied is within approximately $50 \mu$-strain - 4,000 $\mu$-strain ${ }^{31-33}$; this corresponds to 0.6 - $48 \mathrm{MPa}$ compression stress on the cortical bone $(\mathrm{E}=12.0 \mathrm{GPa})$. As per these criteria, the compressive and tensile stress levels applied to the cortical bone in this study were confirmed to be safe for clinical use.

In the present study, FEA was conducted since the two-component OMI has a surface-treated screw. Studies have shown better osseointegration of surfacetreated mini-implants than machined-surface mini-implant. $^{7,12,33}$ Further studies are needed determine the stress distribution during the placement and removal of

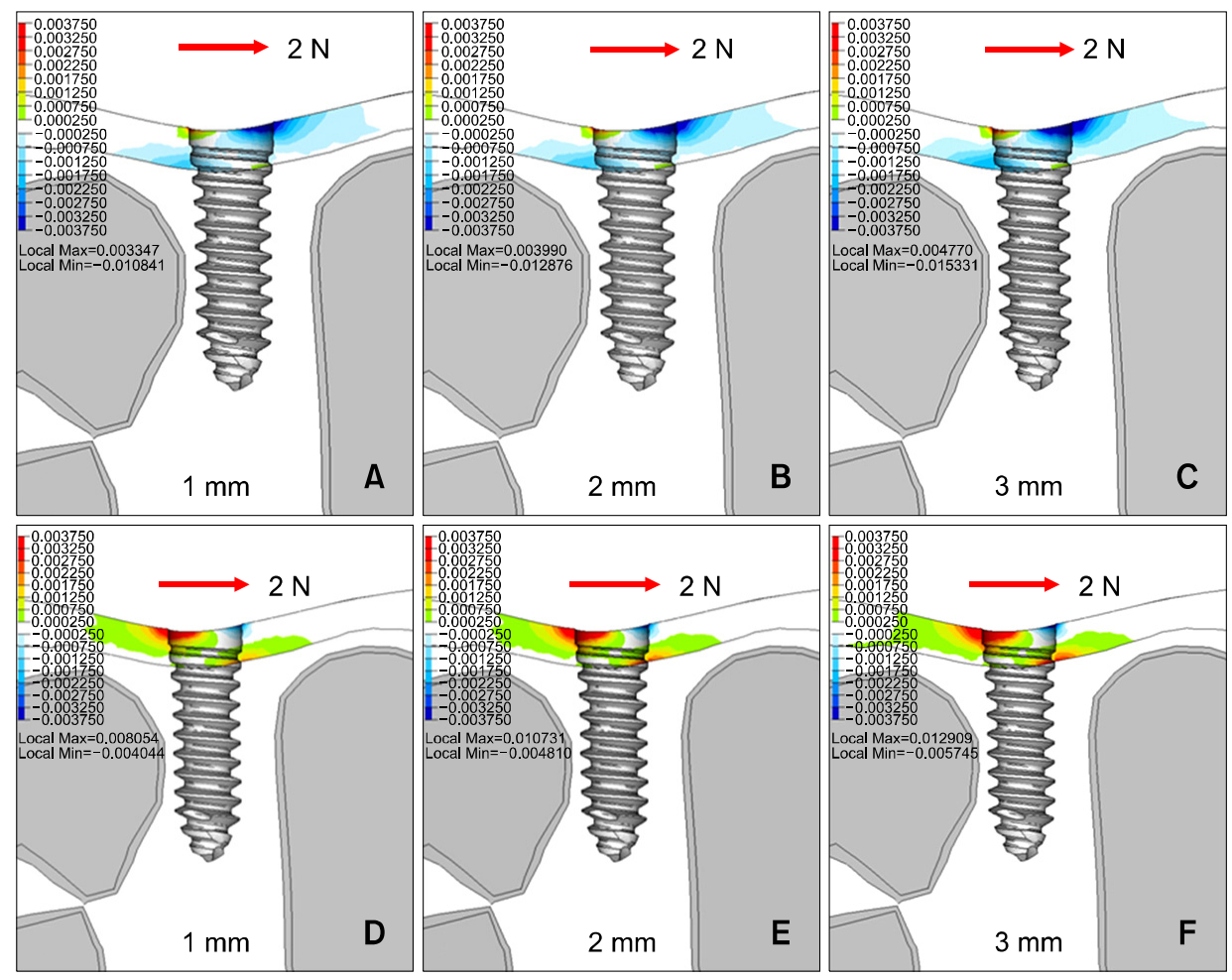

Fig 6. A to C, Contour plots of the minimum principal (compressive) stress to the bone after a $2 \mathrm{~N}$ lateral force is applied; $\mathbf{D}$ to $\mathbf{F}$, contour plots of the maximum principal (tensile) stress to the bone after a $2 \mathrm{~N}$ lateral force is applied. 
surface-treated mini-implants and under various force applications such as rotational force or dynamic force application.

\section{CONCLUSION}

Two-component OMI has clinical benefits because of its replaceable head part. The FEA used in this study showed that the stress to the adjacent bone increased with the increasing head length but was within the physiological limit. Therefore, the two-component OMI can be used for clinical purposes.

\section{REFERENCES}

1. Byloff FK, Kärcher H, Clar E, Stoff F. An implant to eliminate anchorage loss during molar distalization: a case report involving the Graz implant-supported pendulum. Int J Adult Orthodon Orthognath Surg 2000;15:129-37.

2. Creekmore TD, Eklund MK. The possibility of skeletal anchorage. J Clin Orthod 1983;17:266-9.

3. Deguchi T, Takano-Yamamoto T, Kanomi R, Hartsfield JK Jr, Roberts WE, Garetto LP. The use of small titanium screws for orthodontic anchorage. J Dent Res 2003;82:377-81.

4. Kanomi R. Mini-implant for orthodontic anchorage. J Clin Orthod 1997;31:763-7.

5. Costa A, Raffainl M, Melsen B. Miniscrews as orthodontic anchorage: a preliminary report. Int $\mathbf{J}$ Adult Orthod Orthognath Surg 1998;13:201-9.

6. Park HS, Lee SK, Kwon OW. Group distal movement of teeth using microscrew implant anchorage. Angle Orthod 2005;75: 602-9.

7. Park SH, Kim SH, Ryu JH, Kang YG, Chung KR, Kook YA. Bone-implant contact and mobility of surface-treated orthodontic micro-implants in dogs. Korean J Orthod 2008;38: 416-26.

8. Chae JM, Chang NY, Cho JH, Kang KH, Kim SC. Treatment of skeletal Class II adult patient with vertical and transverse problems caused by nasal airway obstruction using microimplant anchorage. Korean J Orthod 2009;39:257-72.

9. Moon CH, Lee JS, Lee HS, Choi JH. Non-surgical treatment and retention of open bite in adult patients with orthodontic mini-implants. Korean J Orthod 2009;39:402-19.

10. Kim SH, Kook YA, Lee W, Kim I, Chung KR. Two-component mini-implant as an efficient tool for orthognathic patients. Am J Orthod Dentofacial Orthop 2009;135:110-7.

11. Kim SH, Cho JH, Chung KR, Kook YA, Nelson G. Removal torque values of surface-treated mini-implants after loading. Am J Orthod Dentofacial Orthop 2008;134:36-43.

12. Kim SH, Lee SJ, Cho IS, Kim SK, Kim TW. Rotational resistance of surface-treated mini-implants. Angle Orthod 2009; 79:899-907.

13. Jeong DM, Choi B, Choo H, Kim JH, Chung KR, Kim SH.
Novel application of the 2-piece orthodontic mini-implant for temporary crown restoration after orthodontic treatment. Am J Orthod Dentofacial Orthop 2011;140:569-79.

14. Ding X, Liao SH, Zhu XH, Zhang XH, Zhang L. Effect of diameter and length on stress distribution of the alveolar crest around immediate loading implants. Clin Implant Dent Relat Res 2009;11:279-87.

15. Ding X, Zhu XH, Liao SH, Zhang XH, Chen H. Implant-bone interface stress distribution in immediately loaded implants of different diameters: a three-dimensional finite element analysis. J Prosthodont 2009;18:393-402.

16. Haack JE, Sakaguchi RL, Sun T, Coffey JP. Elongation and preload stress in dental implant abutment screws. Int J Oral Maxillofac Implants 1995;10:529-36.

17. Kinni ME, Hokama SN, Caputo AA. Force transfer by osseointegration implant devices. Int J Oral Maxillofac Implants 1987;2:11-4.

18. Rieger MR, Mayberry M, Brose MO. Finite element analysis of six endosseous implants. J Prosthet Dent 1990;63:671-6.

19. Sakaguchi RL, Borgersen SE. Nonlinear contact analysis of preload in dental implant screws. Int $\mathrm{J}$ Oral Maxillofac Implants 1995;10:295-302.

20. Motoyoshi M, Inaba M, Ono A, Ueno S, Shimizu N. The effect of cortical bone thickness on the stability of orthodontic mini-implants and on the stress distribution in surrounding bone. Int J Oral Maxillofac Surg 2009;38:13-8.

21. Park JS, Yu WJ, Kyung HM, Kwon OW. Finite element analysis of cortical bone strain induced by self-drilling placement of orthodontic microimplant. Korean J Orthod 2009;39:203-12.

22. Tanne K, Sakuda M, Burstone CJ. Three-dimensional finite element analysis for stress in the periodontal tissue by orthodontic forces. Am J Orthod Dentofacial Orthop 1987;92: 499-505.

23. Poppe M, Bourauel C, Jäger A. Determination of the elasticity parameters of the human periodontal ligament and the location of the center of resistance of single-rooted teeth a study of autopsy specimens and their conversion into finite element models. J Orofac Orthop 2002;63:358-70.

24. Sertgöz A, Güvener S. Finite element analysis of the effect of cantilever and implant length on stress distribution in an implant-supported fixed prosthesis. J Prosthet Dent 1996;76: 165-9.

25. Skalak R. Biomechanical considerations in osseointegrated prostheses. J Prosthet Dent 1983;49:843-8.

26. Merz BR, Hunenbart S, Belser UC. Mechanics of the implant-abutment connection: an 8-degree taper compared to a butt joint connection. Int $\mathrm{J}$ Oral Maxillofac Implants 2000; 15:519-26.

27. Mazor Z, Steigmann M, Leshem R, Peleg M. Mini-implants to reconstruct missing teeth in severe ridge deficiency and small interdental space: a 5-year case series. Implant Dent 2004;13: 336-41.

28. Baurmash H. Bonded arch bars in oral and maxillofacial surgery. An update. Oral Surg Oral Med Oral Pathol 1993;76: 553-6.

29. Seo W, Kim SH, Chung KR, Nelson G. A pilot study of the osseointegration potential of a surface-treated mini-implant: bone contact of implants retrieved from patients. World $\mathrm{J}$ 
Orthod 2009;10:202-10.

30. Chung KR, Choo H, Lee JH, Kim SH. Atypical orthodontic extraction pattern managed by differential en-masse retraction against a temporary skeletal anchorage device in the treatment of bimaxillary protrusion. Am J Orthod Dentofacial Orthop 2011;140:423-32.

31. Shatkin TE, Shatkin S, Oppenheimer BD, Oppenheimer AJ. Mini dental implants for long-term fixed and removable pros- thetics: a retrospective analysis of 2514 implants placed over a five-year period. Compend Contin Educ Dent 2007;28:92-9. 32. Frost HM. Bone's mechanostat: a 2003 update. Anat Rec A Discov Mol Cell Evol Biol 2003;275:1081-101.

33. Sugiura T, Horiuchi K, Sugimura M, Tsutsumi S. Evaluation of threshold stress for bone resorption around screws based on in vivo strain measurement of miniplate. J Musculoskelet Neuronal Interact 2000;1:165-70. 